\title{
Sexual Sensation Seeking, Drug Use and Risky Sex among Detained Youth
}

Dexter R. Voisin ${ }^{1,2 *}$, Kelly King ${ }^{1,2}$, John Schneider ${ }^{2,3}$, Ralph J. DiClemente ${ }^{2,4,5}$ and Kevin Tan

${ }^{1}$ School of Social Service Administration, University of Chicago, USA

${ }^{2}$ STI/HIV Intervention Network, University of Chicago, USA

${ }^{3}$ Departments of Health Studies and Medicine, University of Chicago, USA

${ }^{4}$ Rollins School of Public Health, Emory University, USA

${ }^{5}$ Emory Center for AIDS Research, USA

\begin{abstract}
Sexual sensation seeking has been correlated with drug use and risky sex in a number of populations. However these relationships have had limited examination among adolescents, and to date, have not been explored among detained youth, a group with some of the highest rates of illicit drug use and STIs. To better understand these relationships we utilized A-CASI to collect data on sociodemographics, sexual sensation seeking, drug use and risky sexual behaviors among a sample of 550 detained youth. A series of multivariable regression models controlling for age, gender, race/ethnicity, socioeconomic status and risky peer networks indicated that sexual sensation seeking was associated with alcohol and ecstasy use; having sex while high on drugs; having sex with a partner who was high on drugs; having more sexual partners; having engaged in unprotected vaginal sex; and less condom use during oral sex, all in the 2 months prior to being detained. In addition, sexual sensation seeking was also associated with ever having exchanged sex for drugs or money. These data have important implications for STI/drug use prevention interventions among detained adolescents.
\end{abstract}

Keywords: Sexual sensation seeking; Detained youth; STI risk; Drug use

Abbreviations: HIV: Human Immunodeficiency Virus; STI: Sexually Transmitted Infections; SSS: Sexual Sensation Seeking

\section{Introduction}

In the United States (U.S.), the acquisition of STIs is a major cause of morbidity for adolescents [1]. Moreover, rates of STIs (e.g., Gonorrhea) are 10 times higher among adolescent populations, detained for legal offences when compared to peers without such histories [2]. Risky behaviors such as inconsistent condom use, increased numbers of sex partners, sex while high on drugs, and sex with high-risk partners, are some of the behavioral factors associated with higher STI acquisition, which can have severe negative health and mental health sequelae for adolescents $[1,3,4]$.

Additionally, the presence of STIs such as Gonorrhea and Chlamydia increases the probability of contracting human immunodeficiency virus (HIV) [5] of which adolescents and young adults in 2009 constituted half of all new infections worldwide [6]. Equally, concerning are the high rates of illicit drug consumption (i.e., marijuana, ecstasy, and alcohol) among this population [7]. High rates of drug use not only contribute to risky sex and STI acquisition [3] but also to engaging in transactional sex, which may represent one of the reasons why these youth may come to the attention of juvenile justice authorities [8].

Given the high rates of STIs/HIV and drug use among adolescents, there is an increasing interest in the role of personality dispositions such as sexual sensation seeking (SSS) and its relationship to risky behaviors [9]. Sexual sensation seeking (SSS) is defined as a fondness for thrilling, optimal, and novel levels of sexual stimulation and arousal [10]. Persons prone to SSS are often predisposed to excessive drinking, are adventurous and frequently seek novel and different sexual experiences. Consequently such persons may engage in unprotected sex with multiple partners and illegal drug use as means of satisfying their desire for novel arousal and stimulation [11-13].

A number of studies, mostly with gay and bisexual men, have documented that SSS is a reliable and consistent predictor of drug use and risk sexual behaviors [10,14-19]. However, there remains a dearth of studies related to SSS and risky sex with heterosexual youth and especially among females [20,21]. Moreover to date, no studies have examined the relationship between sensation seeking and drug use and risky sex among detained youth. This represents a significant gap in the literature, given that in general, detained youth compared to nondetained counterparts might be prone to engaging in more sensation seeking behaviors (e.g., robberies, muggings, vandalism, drug use and sex work) which may represent some of the reasons why they become detained.

Therefore the primary aim of this study was to examine whether SSS was related to drug use and risky sex among detained youth. Populations who are at high risk for STI and HIV but are underrepresented in the extant literature. In examining these relationships we controlled for the potential confounding effects of age, gender, peer norms and race/ ethnicity. Prior research has found that drug use and risky sex increases with age [22]. Furthermore, the few studies with college students have consistently documented that males score higher than females on SSS have more sexual partners and drink more alcohol [23,24]. In addition, risky peer norms have been consistently documented to be a significant factor predicting drug use and risky sex [24]. Prior research has also noted some racial/ethnic differences with regards to established makers for STIs. For instance, African American youth report a higher number

${ }^{*}$ Corresponding author: Dexter R. Voisin, Ph.D, School of Social Service Administration, University of Chicago, 969 East 60th Street, Chicago, IL 60637, USA, Tel: 773-702-1124; Fax: 773-702-0874; E-mail: d-voisin@uchicago.edu

Received May 08, 2012; Accepted August 25, 2012; Published August 29, 2012

Citation: Voisin DR, King K, Schneider J, DiClemente RJ, Tan K (2012) Sexual Sensation Seeking, Drug Use and Risky Sex among Detained Youth. J AIDS Clinic Res S1:017. doi:10.4172/2155-6113.S1-017

Copyright: (c) 2012 Voisin DR, et al. This is an open-access article distributed under the terms of the Creative Commons Attribution License, which permits unrestricted use, distribution, and reproduction in any medium, provided the original author and source are credited. 
of sexual partners but higher rates of condom use compared to their white peers $[25,26]$.

\section{Materials and Methods}

Between October 2001 and July 2003, youth were recruited from 8 of 21 regional youth detention centers (RYDCs) in the Atlanta, Georgia area. These centers were located in areas ranging from rural to urban. At that time in Georgia, the male to female ratio of detained youth was approximately 3 to 1 with RYDCs serving a maximum of 30 youth. The 8 RYDCs selected to participate in the study had a higher maximum capacity and therefore had more detained female adolescents to sample $(2: 1)$.

Participants were recruited for the study if they were 14 to 18 years old, had been enrolled in school prior to being detained, had been detained within the last 3 days, self-identified as heterosexual, and had a parent or guardian who provided verbal consent over the phone. Recruitment efforts occurred no more than once each week at each of the eight facilities. Research assistants specifically recruited only adolescents who were admitted within the last three days. Only adolescents who expressed willingness to participate proceeded in the study.

We were able to contact a total of 791 parents, with 725 (92\%) providing their consent. Contacting a parent or legal guardian was a challenge and involved several attempts made by the research assistants over the course of a week. By Institutional Review Board (IRB) agreement, research assistants were permitted to obtain this consent by phone. Thus, by the time we made contact and obtained verbal consent, some youths had been released. As a result, we were able to approach 682 youths who met study criteria and for whom we had parental consent. Of those, $554(81 \%)$ agreed to participate. The analytic sample comprised 550 participants who self-identified as heterosexual.

By agreement with Emory University's IRB, neither participants nor their legal guardians were compensated for study enrollment, and research assistants were permitted to obtain that consent by phone. The IRBs at Emory University and the Georgia Department of Juvenile Justice approved all study procedures.

\section{Data collection}

All self-reported measures were collected using audio-computer assisted self-interviewing (A-CASI). By providing a voice track that delivered each question to adolescents through headphones, A-CASI technology may have reduced problems that would otherwise have been posed by illiteracy. The technology also creates a user-friendly interview method that automatically handles skip patterns in the questionnaire and provides adolescents with an interactive experience, possibly increasing task attentiveness, completion of survey and reducing response bias [27]. Adolescents' responses to the computer-delivered questions were automatically encrypted to ensure confidentiality.

\section{Measures}

Independent variable: Sexual sensational seeking was assessed by a 9 item-scale, which has been validated with adolescents. The scale included the following items "I enjoy having sex spur of the moment", "Having sex with a new partner is exciting to me", "Stopping to use a condom takes the fun out of sex", "When it comes to sex I am willing to try anything", "I act out sexual scenes from movies/videos", "I like to try new positions when having sex", "I enjoy the thrill of having sex in public places", "I use sex toys to make sex more exciting", and "I have sex with partners I meet on chat-lines or the internet". Participants indicated their level of agreement on a Likert scale [1=Strongly disagree; $4=$ Strongly agree; Cronbach's alpha $=0.75]$ [28].

Dependent variables: Several dependent variables were assessed within the last two months, in order to minimize recall errors. All measures were assessed for both males and females.

a) Drug use: Five separate items assessed drug-use behaviors in the 2 months prior to being detained. Participants were asked if they had used alcohol, amphetamines, ecstasy, or marijuana. The response format for each item was $0=$ no or $1=$ yes.

b) STI-related factors: Number of sexual partners in the last two months, was measured by one item. How many sexual partners did you have in the last 2 months, prior to being detained?

c) Condom use: Condom use was assessed using two items. First, by asking participants how many times they engaged in unprotected vaginal sex during the two months prior to detainment, with scores ranging from 0-50. Responses to this item were recorded such that $0=$ Did not engage in unprotected vaginal sex and $1=\mathrm{Had}$ unprotected vaginal sex at least once in the two months prior to detainment, given the reality that even one unprotected sexual encounter places participants at risk for STIs/HIV. Condom use during oral sex was also assessed with the item, "In the two months before coming to this center, how many times did you use a condom during oral sex." Scores ranged from 0-18 and responses were recorded such that $1=$ Never used a condom during oral sex and $0=\mathrm{Had}$ protected oral sex at least once in the two months prior to detainment.

Sex while high on drugs was assessed by one item. Have you ever had sex while high on drugs, in the 2 months prior to being detained? ( $0=$ no or $1=$ yes).

Sex with a partner high on drugs was assessed by one item. Have you ever had sex with a partner who was high on drugs, in the 2 months prior to being detained? ( $0=$ no or $1=y e s)$.

Exchanged sex for money or drugs was measured by two items. Have you ever exchanged sex for money? Have you ever exchanged sex for drugs? ( $0=$ no or $1=y e s)$.

Covariates: Covariates assessed were age, gender, race/ethnicity, socioeconomic status, and peer networks. Age was assessed by one item "What is your age?" Gender was assessed by one question, "What is your gender?" with response choices, "Male" or "Female." Race/ ethnicity was based on one item, "What is your race/ethnicity?" with response categories, "White-non-Hispanic", "Black-non-Hispanic", "White-Hispanic", "Black-Hispanic", "Asian-American", "Native American" and "Other." Race was subsequently dummy coded into $0=$ non-Hispanic white and $1=$ ethnic minority youth. Socioeconomic status was assessed by the question "do you or would you qualify for free or reduced lunch at school?" The response format was $0=$ no or $1=y e s$. Risky peer networks were assessed by a five-item scale [29] (for example, "Most of the girls I know never use condoms when they have sex"). Participants responded on a five-point Likert scale, ranging from $1=$ strongly disagree to $5=$ strongly agree. This scale had strong internal levels of inter-item reliability (Cronbach's alpha $=0.86$ ).

Statistical analyses: First, descriptive statistics were calculated for all major study variables. Pearson correlations were used to examine the relationships between SSS and all major dependent variables. Multicolinearity was not detected among any variables. Next, using a series of logistic and hierarchical regression models we examined the relationship between SSS and drug use and STI-related risk behaviors, 
calculating adjusted odds ratios, their $95 \%$ confidence intervals, and respective P-values. In all analyses we controlled for the potential effects of age, gender, race/ethnicity, socioeconomic status and risky peer networks [30]. All data were analyzed using SPSS version 18.0.

\section{Results}

\section{Descriptive analyses}

The analytic sample comprised 550 adolescents. Of the total sample, half were female adolescents (50\%), and $41 \%$ were identified as non-Hispanic white. The average age of participants was 15.4 years $(\mathrm{SD}=0.96)$. More than half $(57.5 \%)$ of overall participants indicated eligibility for free school lunch. Peer risk norms ranged from 8 to 32 with a mean score of 19.77 for the sample. Among all sexually active participants $(\mathrm{N}=486,85.9 \%) \mathrm{N}=226,84.3 \%$ were males and $\mathrm{N}=242$, $87.4 \%$ were females. In terms of drug use behaviors, $73.3 \%$ of this sample used alcohol, while $23.3 \%$ reported having used ecstasy at least

\begin{tabular}{|l|c|c|}
\hline & \multicolumn{2}{|c|}{ Total } \\
\hline Variables & N & $\%$ \\
\hline Gender & 550 & 100 \\
$14-15$ & 292 & 53.3 \\
$16-17$ & 149 & 45.4 \\
18 & 7 & 1.3 \\
\hline Race & & \\
Ethnic Minority & 324 & 59.2 \\
Non-Hispanic White & 223 & 40.8 \\
\hline Free school lunch & 314 & 57.5 \\
\hline Substance Use ${ }^{\text {a }}$ & & \\
Alcohol & 352 & 73.3 \\
Amphetamine & 50 & 10.4 \\
Ecstasy & 112 & 23.3 \\
Marijuana & 394 & 81.9 \\
\hline Sexual Behaviors ${ }^{\text {a,b }}$ & & \\
Number of sexual partners & 221 & 81.8 \\
Unprotected vaginal sex & 270 & 55.5 \\
Unprotected oral sex & 194 & 88.2 \\
\hline Ever had sex while high & 339 & 62.2 \\
Ever had sex while partner high & 324 & 59.6 \\
Ever exchanged sex for drugs & 33 & 7.1 \\
Ever exchanged sex for money & 48 & 10.3 \\
\hline
\end{tabular}

" $P<0.05, \quad " P<0.01$

1 missing data with some items

aln the 2 months prior to being detained

${ }^{b}$ Assessed only for participants who reported having had vaginal sex Table 1: Demographic characteristics of detained youth $(N=550)^{1}$. once. As far as sexual behaviors, the mean number of sexual partners participants had in the last 2 months was $2.57 ; 55.5 \%$ had engaged in unprotected vaginal sex; $88.2 \%$ had engaged in unprotected oral sex; $62.2 \%$ had sex while high on alcohol or drugs; $59.6 \%$ had sex with a partner who was high on alcohol or other drugs; $7.1 \%$ reported ever having exchanged sex for drugs, and $10.3 \%$ had ever exchanged sex for money (Table 1). In addition, the SSS mean was 19.38, median 19.0, mode 21.0 , range $9-36, \mathrm{SD}=4.79$.

\section{Bivariate analyses}

Bivariate correlations were calculated between SSS and each drug and sexual risk outcome variables among the overall sample. Analyses indicated that SSS was correlated with alcohol use $(\mathrm{p}<0.001)$, ecstasy use $(\mathrm{p}<0.001)$, having sex while high $(\mathrm{p}<0.001)$, having sex with a partner who is high $(\mathrm{p}<0.001)$, exchanging sex for drugs $(\mathrm{p}=0.001)$, exchanging sex for money $(\mathrm{p}=0.006)$, number of sexual partners in the last two months $(\mathrm{p}<0.001)$ and frequency of unprotected vaginal sex $(p=0.007)$. Age $(p=0.007)$, gender $(p<0.001)$, race $(p=0.018)$, peer risk norms $(\mathrm{p}=0.023)$ and SES $(\mathrm{p}=0.004)$ were also significantly correlated with SSS. These correlations were higher for older youth, males, those reporting riskier peer norms, white-non Hispanics and individuals with higher SES.

\section{Regression analyses}

To determine if SSS contributed significant variance to drug use and risky sex beyond the effects of age, race/ethnicity, gender, SES and risky peer norms, we conducted a number of hierarchical and logistic regression models for each outcome, controlling for these covariates. Results showed that sexual sensation seeking was associated with alcohol and ecstasy use in the two months prior to being detained. Additionally, SSS was associated with a constant pattern of sexual risk behaviors within the last two months prior to being detained. More specifically, SSS was related to having more sexual partners; having engaged in unprotected vaginal and oral sex; having sex while high on drugs; having sex with a partner who was high on drugs; exchanging sex for drugs; and exchanging sex for money (Table 2).

\section{Discussion}

To date, this is the first study to examine the relationship between SSS and drug use and risky sex among detained youth. We examined these relationships using a broad spectrum of drug use and STI-

\begin{tabular}{|c|c|c|c|c|c|c|c|}
\hline \multirow[t]{2}{*}{ Variables $^{a}$} & \multicolumn{4}{|c|}{ Bivariate analyses Sexual Sensation Seeking } & \multicolumn{3}{|c|}{ Multivariate analyses } \\
\hline & Mean & SD & $r$ & $p$ & $\mathrm{AOR}^{\mathrm{c}}$ & $95 \% \mathrm{Cl}^{\mathrm{d}}$ & $p$ \\
\hline $\begin{array}{l}\text { Substance use } \\
\text { Alcohol } \\
\text { Amphetamines } \\
\text { Ecstasy } \\
\text { Marijuana }\end{array}$ & $\begin{array}{l}0.77 \\
0.13 \\
0.26 \\
0.90\end{array}$ & $\begin{array}{l}0.42 \\
0.33 \\
0.44 \\
0.29\end{array}$ & $\begin{array}{l}0.216 \\
0.251 \\
0.248 \\
0.141\end{array}$ & $\begin{array}{l}0.000 \\
0.000 \\
0.000 \\
0.002\end{array}$ & $\begin{array}{l}1.12 \\
1.09 \\
1.12 \\
1.06\end{array}$ & $\begin{array}{c}1.05,1.19 \\
0.994,1.20 \\
1.05,1.18 \\
0.986,1.15\end{array}$ & $\begin{array}{l}0.000 \\
0.067 \\
0.000 \\
0.113\end{array}$ \\
\hline $\begin{array}{l}\text { Sexual Behaviors } \mathrm{a}, \mathrm{b} \\
\text { Number sex partners } \\
\text { Unprotected vaginal sex } \\
\text { Unprotected oral sex } \\
\text { Sex while high } \\
\text { Sex while partner high } \\
\text { Exchanged sex for drugs } \\
\text { Exchanged sex for money }\end{array}$ & $\begin{array}{l}2.57 \\
0.57 \\
0.36 \\
0.56 \\
0.53 \\
0.07 \\
0.10\end{array}$ & $\begin{array}{c}4.52 \\
0.496 \\
1.51 \\
0.497 \\
0.499 \\
0.26 \\
0.304\end{array}$ & $\begin{array}{l}0.241 \\
0.163 \\
0.059 \\
0.306 \\
0.220 \\
0.155 \\
0.127\end{array}$ & $\begin{array}{l}0.000 \\
0.007 \\
0.382 \\
0.000 \\
0.000 \\
0.001 \\
0.006\end{array}$ & $\begin{array}{l}0.27 \\
1.09 \\
1.07 \\
1.15 \\
1.15 \\
1.18 \\
1.15\end{array}$ & $\begin{array}{c}0.136,0.404 \\
1.02,1.17 \\
1.01,1.14 \\
1.09,1.21 \\
1.09,1.22 \\
1.08,1.29 \\
1.06,1.24\end{array}$ & $\begin{array}{l}0.000 \\
0.010 \\
0.014 \\
0.000 \\
0.000 \\
0.000 \\
0.001\end{array}$ \\
\hline
\end{tabular}

${ }^{1}$ Missing data with some items

${ }^{a}$ In the 2 months prior to being detained

${ }^{\mathrm{b}}$ Assessed only for participants who reported having had vaginal sex

${ }^{c}$ Adjusted odds ratio (AOR) controlling for age, gender, race/ethnicity, eligibility for free school lunch, and risky peer norms.

${ }^{\mathrm{d}} \mathrm{Cl}=$ confidence interval

Table 2: Associations between sexual sensation seeking, drug use, and risky sex among detained adolescents $(\mathrm{N}=550)^{1}$. 
Citation: Voisin DR, King K, Schneider J, DiClemente RJ, Tan K (2012) Sexual Sensation Seeking, Drug Use and Risky Sex among Detained Youth. J AIDS Clinic Res S1:017. doi:10.4172/2155-6113.S1-017

related risk behaviors, which are rarely collectively assessed across a single adolescent sample. Our findings corroborate those of earlier studies of MSM and adolescent African American females [14-16,20] documenting that SSS is a significant correlate of a number of at-risk behaviors such as drug use and risky sex. Results indicated that SSS was related to using drugs such as alcohol and ecstasy. Alcohol is generally considered a depressant and ecstasy has the features of both a stimulant and mild depressant [31-33]. Interestingly, we noted no significant relationships between SSS and amphetamine and marijuana use. There are several possible explanations for these findings. Amphetamine use was very low among this sample and small numbers may have been inadequate to detect any potential relationships. Additionally, although marijuana use was prevalent among this sample, this drug can have the features of a mild depressant but may also make users feel nervous or even paranoid [34]. Therefore, sexual sensation seekers who may attempt to calm their heightened emotional states, or want to feel emotionally stimulated, may find the effects of marijuana less desirable. However, future research will be needed to clarify this finding.

In addition, findings indicated that SSS was related to consistent patterns of risky sexual behaviors such as having more sex partners, having unprotected vaginal sex, engaging in unprotected vaginal and oral sex, having sex while being high, having sex with a partner who was high, exchanging sex for drugs, and exchanging sex for money. Youth who come into contact with juvenile justice authorities in general may be high risk takers and pleasure seekers. Without question there are structural determinants that influence drug use and STI-related risk behaviors (e.g., poverty, lack of access to health care and education, marginalization, etc). However, our study findings indentified SSS as an individual trait that distinguished participants who engaged in drug use and risky sex even after controlling for the confounding effects of age, gender, race/ethnicity and poverty [22-26].

This study has several important intervention implications. However, we should first note a few study limitations. First, the use of a convenience sample, necessitated by the need to obtain prior parental consent, may have resulted in a biased sample. Although participants who refused participation did not differ on demographic factors from those who enrolled in the study. Potential study bias, may limit the ability to generalize findings to the larger population of detained youth in Georgia, as well as the larger population of detained youth across the country. Additionally, although self-report measures are widely used in behavioral research, they pose limitations related to recall error, bias and underreporting. As a result, we utilized sophisticated A-CASI technology in order to minimize some of these limitations, nevertheless some of these limits were still present. Furthermore, findings are limited by the cross-sectional study design, which does not allow for inferred causality between SSS and drug use and risky sex. Finally, the present study focused specifically on unprotected vaginal and oral sex as behavioral risk outcomes. However, unprotected anal intercourse (UAI) also places adolescents at increased sexual risk. Therefore future studies should also assess relationships between SSS and UAI.

Notwithstanding these limitations, these findings have important implications for STI prevention/intervention for detained youth. The majority of drug and STI prevention programs focus on cognitive behavioral approaches [21]. However, these findings corroborate that SSS is a significant factor associated with illicit drug and risky sex among a detained adolescents. Consequently, in addition to developing programs that promote prevention information and skills, it is also important to address the needs of participants who may express a desire for fun, novel and existing types of sexual arousal. Consequently prevention programs should encourage sensation seekers to find ways to eroticize safer sexual behavior and bring new excitement to it [14]. Additionally, there is a greater need to educate persons on alternative, less risky, yet novel sexual behaviors [20]. Ultimately, addressing the relationship between SSS and risk behavior among detained adolescents is crucial to developing effective interventions and improving sexual health outcomes among this high risk population.

\section{Acknowledgements}

This research was supported in part, by the Emory Center for AIDS Research (NIH/NIAID 2 P30 Al50409-04A1), the Rural Center for AIDS/STD Prevention at Indiana University, a grant from the University Research Council at Emory University, and by a grant award to the Center for AIDS Prevention Studies R25 HD045810-02.

\section{References}

1. Centers for Disease Control and Prevention (2009) Sexually transmitted disease surveillance 2008. CDC, USA.

2. Centers for Disease Control and Prevention (2009) Sexually transmitted diseases in the United States, 2008. CDC Fact Sheet, USA.

3. Besculides M, Laraque $F$ (2004) Unintended pregnancy among the urban poor J Urban Health 81: 340-348.

4. Koniak-Griffin D, Brecht ML (1995) Linkages between sexual risk taking substance use, and AIDS knowledge among pregnant adolescents and young mothers. Nurs Res 44: 340-346.

5. Centers for Disease Control and Prevention. The role of STD detection and treatment in HIV prevention - CDC fact sheet.

6. United Nations Program on HIVIAIDS (UNAIDS) and World Health Organization (WHO) (2012) AIDS Epidemic Update 2009.

7. Centers for Disease Control and Prevention (2010) Youth Risk Behavior Surveillance---United States 2009. MMWR 59: 1-142.

8. Romero-Daza N, Weeks M, Singer M (2003) "Nobody gives a damn if I live or die": Violence, drugs, and street-level prostitution in inner-city Hartford, Connecticut. Med Anthropol 22: 233-259.

9. Wingood GM, DiClemente RJ (1998) The influence of psychosocial factors alcohol, drug use on African-American women's high-risk sexual behavior. Am J Prev Med 15: 54-59.

10. Kalichman SC, Johnson JR, Adair V, Rompa D, Multhauf K, et al. (1994) Sexua sensation seeking: Scale development and predicting AIDS-risk behavior among homosexually active men. J Pers Assess 62: 385-397.

11. Boyle JR, Murray C, Boekeloo BO (2002) Alcohol use, sexual relationship type, discussion of sexual risks, and condom use among college students. Proceedings of the 130th American Public Health Association.

12. Reece M, Dodge B, Cole SL (2002) Sexual compulsivity and college population Implications for mental health providers. 130th Annual Meeting of the American Public Health Association.

13. Kalichman SC, Rompa D (1995) Sexual sensation seeking and sexua compulsivity scales: Reliability, validity, and predicting HIV risk behavior. J Pers Assess 65: 586-601.

14. Chng CL, Géliga-Vargas J (2000) Ethnic identity, gay identity, sexual sensation seeking and HIV risk taking among multiethnic men who have sex with men. AIDS Educ Prev 12: 326-339.

15. Kalichman SC, Heckman T, Kelly JA (1996) Sensation seeking as an explanation for the association between substance use and HIV-related risky sexual behavior. Arch Sex Behav 25: 141-154

16. McCoul MD, Haslam N (2001) Predicting high risk sexual behaviour in heterosexual and homosexual men: The roles of impulsivity and sensation seeking. Pers Indiv Differ 31: 1303-1310.

17. Crawford I, Hammack PL, McKirnan DJ, Ostrow D, Zamboni BD, et al. (2003) Sexual sensation seeking, reduced concern about HIV and sexual risk behaviour among gay men in primary relationships. AIDS Care 15: 513-524.

18. Dolezal C, Meyer-Bahlburg HFL, Remien RH, Petkova E (1997) Substance use 
Citation: Voisin DR, King K, Schneider J, DiClemente RJ, Tan K (2012) Sexual Sensation Seeking, Drug Use and Risky Sex among Detained Youth. J AIDS Clinic Res S1:017. doi:10.4172/2155-6113.S1-017

Page 5 of 5

during sex and sensation seeking as predictors of sexual risk behavior among HIV+ and HIV- gay men. AIDS Behav 1: 19-28.

19. Kalichman SC, Weinhardt L, DiFonzo K, Austin J, Luke W (2002) Sensation seeking and alcohol use as markers of sexual transmission risk behavior in HIV-positive men. Ann Behav Med 24: 229-235.

20. Spitalnick JS, DiClemente RJ, Wingood GM, Crosby RA, Milhausen RR, et al. (2007) Brief report: Sexual sensation seeking and its relationship to risky sexual behaviour among African-American adolescent females. J Adolesc 30: 165-173.

21. Gullette DL, Lyons MA (2005) Sexual sensation seeking, compulsivity, and HIV risk behaviors in college students. J Community Health Nurs 22: 47-60.

22. Gruber J (2001) Risky behavior among youths: An economic analysis. MA: MIT Press, Cambridge.

23. Arnold P, Fletcher S, Farrow R (2002) Condom use and psychological sensation seeking by college students. Sex Relation Ther 17: 355-365.

24. Rolison MR, Scherman A (2002) Factors influencing adolescents' decisions to engage in risk-taking behavior. Adolescence 37: 585-596.

25. Flom PL, Friedman SR, Kottiri BJ, Neaigus A, Curtis R (2001) Recalled adolescent peer norms towards drug use in young adulthood in a low-income, minority urban neighborhood. J Drug Issues 31: 425-444.

26. Voisin D, Sung Hong J, King K (2012) Factors associated with sexual health risk and STIs among detained youth: A Review. Child Youth Serv Rev 10: 1983 1991.

27. Brewster KL (1994) Race differences in sexual activity among adolescent women: The role of neighborhood characteristics. Am Sociol Rev 59: 408-424

28. Kissinger P, Rice J, Farley T, Trim S, Jewitt K, et al. (1999) Application of computer-assisted interviews to sexual behavior research. Am J Epidemiol 149: 950-954.

29. DiClemente R, Milhausen RR, Salazar LF, Spitalnick J, McDermott Sales J, et al. (2010) Development of the sexual sensation-seeking scale for African American adolescent women. Int J Sex Health 22: 248-261.

30. DiClemente RJ, Wingood GM, Crosby RA, Sionean C, Brown LK, et al. (2010) A prospective study of psychological distress and sexual risk behavior among black adolescent females. Pediatrics 108: E85.

31. Hosmer DW, Lemeshow S (2000) Applied logistic regression. John Wiley \& Sons, New York.

32. Sadava SW, Thistle R, Forsyth R (1978) Stress, escapism and patterns of alcohol and drug use. J Stud Alcohol 39: 725-736.

33. Cohen RS (1995) Subjective reports on the effects of the MDMA ('ecstasy') experience in humans. Prog Neuropsychopharmacol Biol Psychiatry 19: 1137 1145

34. Hall W, Solowij N (1998) Adverse effects of cannabis. Lancet 352: 1611-1616. 